\title{
Effects of Root Extracts from Panax ginseng C. A. Meyer (Araliaceae) of Different Ages on K562 Cells
}

\author{
Xunan Lyu ${ }^{1}$, Yizhen Zhang ${ }^{2}$, Qing Mu $^{2}$, Zhou Cheng ${ }^{3}$, Jiakuan Chen ${ }^{1}$, Wenju Zhang ${ }^{1 *}$ \\ ${ }^{1}$ Ministry of Education, Key Laboratory for Biodiversity Science and Ecological Engineering, Institute of Biodiversity Science, \\ School of Life Sciences, Fudan University, Shanghai, China; ${ }^{2}$ School of Pharmacy, Fudan University, Shanghai, China; ${ }^{3}$ School of \\ Life Science and Technology, Tongji University, Shanghai, China. \\ Email: ${ }^{*}$ wjzhang@fudan.edu.cn
}

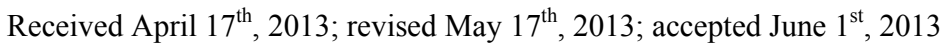

Copyright (C) 2013 Xunan Lyu et al. This is an open access article distributed under the Creative Commons Attribution License, which permits unrestricted use, distribution, and reproduction in any medium, provided the original work is properly cited.

\begin{abstract}
It is well accepted in China that elder ginsengs have more bioactivity and value than younger ones. However, there is little research about the comparison of beneficial effects of ginsengs with different ages. In this study, ginseng root extracts (GRE) were extracted from ginsengs of 5, 8, 12, 14, and 16 years old, respectively, using $55 \%$ ethanol and their effects on human leukemic K562 cells within 48 hours were tested by using Cell Counting Kit-8. The results show that there are significant increases in the cell viability of all the GRE groups compared with Control group within 32 hours. Furthermore, the growth curves of GRE groups were obviously distinct from each other. The cell viability of 5-year-old and 8-year-old GRE groups kept a rapid increase while that of 16-year-old GRE group showed a strong fluctuation within 28 hours. Our results demonstrate that root extracts from ginsengs of different ages contain different bioactivity constituents and have different effects on cell.
\end{abstract}

Keywords: Panax ginseng; Root Extracts; Ages; K562 Cell Line

\section{Introduction}

Panax ginseng C. A. Meyer (ginseng) is a famous herbal medicine with a wide range of therapeutic benefits, such as inhibiting tumor growth, regulating immune system, inducing the cell differentiation, etc. [1,2]. It is well accepted that elder ginsengs have more bioactivity and value than younger ones based on Chinese conventional concept; however, there is little research about the comparison of beneficial effects of ginsengs with different ages.

K562 cell line was established from a patient with chronic myelogenous leukemia and has been widely used both in vitro experiments at present [3]. Ginsenosides and polysaccharides are regarded as the primary active ingredients of ginseng [1,2]. Total ginsenosides of ginseng could not only inhibit the proliferation of K562 cells but also induce the differentiation by inhibiting the expression of erythropoietin receptor protein [4,5]. Moreover, studies have provided clear evidence that polysaccharides from Ginseng also exert antiproliferative activeity against K562 cells at a certain concentration range in

\footnotetext{
${ }^{*}$ Corresponding author.
}

vitro experiment [6,7]. Except for ginsenosides and polysaccharides, ginseng roots also contain some other constituents such as peptides, polyacetylenic alcohols, flavones, and fatty acids which also contribute to a wide range of beneficial effects of ginseng [1,2]. However, the general effects of ginsengroot extracts (GRE) on K562 cells have not been previously investigated.

The purpose of this study was to compare the effects of GRE of different ages on K562 cell line.

\section{Materials and Methods}

\subsection{Sample Collection}

Roots of ginsengwere collected from Huairen and Ji'an, Jilin province, China respectively (shown in Table 1). These ginsengs grew in the same cultivated condition. Roots of ginseng were dried at $50^{\circ} \mathrm{C}$ and were preserved at $-20^{\circ} \mathrm{C}$. Each group consists of 5 individuals except H16 group (4 individuals).

\subsection{Root Extracts of Ginsengs}

Ginseng samples of different ages were dried at $50^{\circ}$ Cand crushed (40 mesh sieve), respectively. Each above sam- 
ple was accurately weighed $6.000 \mathrm{~g}$ and $18.2 \mathrm{~mL} / \mathrm{g}$ of $55 \%$ ethanol was added. After soaking 12 hours at room temperature, the sample suspension was extracted under ultrasonic for $42 \mathrm{~min}$, then centrifuged and the supernatant was collected. The extraction was repeated four times. The supernatants were merged and evaporated to dryness under vacuum at temperature $45^{\circ} \mathrm{C}$. The dried ginseng extracts were accurately weighed to calculate the contents of total GRE and used as pharmacological experiments. A stock solution was prepared by dissolving GRE in $\mathrm{ddH}_{2} \mathrm{O}$ and stored at $-20^{\circ} \mathrm{C}$. To analysis amount in different polarity, the extract resin was resuspended in $30 \mathrm{~mL}$ distilled water and then partitioned with chloroform $(30 \mathrm{~mL} \times 3)$. The chloroform extracts were merged together and dried in a vacuum at $45^{\circ} \mathrm{C}$ and weighed accuratelyto calculate the contents, then stored at $4^{\circ} \mathrm{C}$. The above remains of the ginseng extracts aqueous were then extracted with butanol $(30 \mathrm{~mL} \times 3)$. The final remains of the ginseng extracts aqueous were removed to dry and weighed accuratelyto calculate the contents.

\subsection{Cell Culture and Cell Growth Curve Detection}

K562 human leukemia cell line was obtained from Shanghai Institute of Cell, Chinese Academy of Sciences. Cells were cultured in RPMI-1640 medium (Gibco-BRL, Gaithersburg, MD) supplemented with $10 \%$ fetal bovine serum (Gibco-BRL), $100 \mu \mathrm{g} / \mathrm{ml}$ streptomycin (Sigma Chemical Co., St. Louis, MD) and $100 \mathrm{IU} / \mathrm{ml}$ penicillin (Sigma) at $37^{\circ} \mathrm{C}$. Cells were seeded at $1 \times 10^{5}$ cells/well in 96-well plate for 48 hours with or without a final concentration of $1 \mathrm{mg} / \mathrm{ml} \mathrm{GRE} \mathrm{named} \mathrm{Control} \mathrm{group,} \mathrm{H5}$ (5-year-old) group, H8 (8-year-old) group, H12 (12-yearold) group, H14 (14-year-old) group and H16 (16-yearold) group respectively. Each group had 6 repeats. Cell viability was analyzed by Cell Counting Kit-8 (CCK-8, Dojindo, Kumamoto, Japan) every 4 hours within 48 hours.

\subsection{Statistical Analysis}

Results were expressed as the mean \pm standard deviations (SD). The effect on each parameter was examined by one-way analysis of variance (ANOVA) and independent-sample $t$ test. $\mathrm{P}$ values less than 0.05 were considered statistically significant.

\section{Results}

\subsection{Content of Total GRE and Their Constituents}

Table 1 shows contents of total GRE in ginseng of different age groups. H5 group (5-year-old) has the lowest content $(30.87 \%)$ and H16 group (16-year-old) has the highest $(46.43 \%)$. Contents of ginsenosides and polysaccharides in GRE were measured and results were showed in table. H16 group has the highest content of ginsenosides in GRE (16.11\%) while H5 has the highest content ofpolysaccharides (56.37\%).

\subsection{Cell Viability of K562 Cells within 48 Hours}

Compared with the cell viability of Control group, there were significant increases in all groups treated with 1 $\mathrm{mg} / \mathrm{ml} \mathrm{GRE} \mathrm{between} \mathrm{the} \mathrm{32-hour} \mathrm{point} \mathrm{and} \mathrm{the} \mathrm{48-hour}$ point (data shown in supplementary Table 1). However, growth curves of groups treated with GRE of different ages were obviously distinct from each other within 48 hours.

\subsection{Cell growth Curves of $\mathrm{H} 5$ and $\mathrm{H} 8 \mathrm{GRE}$ Groups}

Compared with Control group, H5 group and H8 group, which possessed similar growth curves, had significant proliferation in cell viability within 48 hours except at the 4-hour point when H5 group had no significant difference with Control group. Furthermore, the cell viability of H8 group was significantly increased compared with that of $\mathrm{H} 5$ group within 24 hours and had no significant difference from the 28 -hour point to the 48 -hour point (Figure 1).

\subsection{Cell Growth Curve of H12 GRE Group}

There was a cyclical fluctuation with a period of 8 hours in the growth curve of H12 group within 24 hours. Compared with Control group, there was no significant difference within 28 hours in cell viability except at the 12hour point when the cell viability of H12 group was significantly decreased. After 28 hours, the growth curve grew slowly. Moreover, the cell viability of $\mathrm{H} 12$ group was always significantly higher than that of Control group but lower than that of other GRE groups after 32 hours.

Table 1. Location, age, individual number, voucher specimen, and collection time of materials used in this study.

\begin{tabular}{cccccc}
\hline Groups & Age (years) & Location & Individual & Voucher specimen. & Collection Time \\
\hline H5 & 5 & Ji'an, Jilin & 5 & JR1 & 2006 \\
H8 & 8 & Huairen, Jilin & 5 & HR5 & 2004 \\
H12 & 12 & Huairen, Jilin & 5 & HR6 & 2004 \\
H14 & 14 & Huairen, Jilin & 5 & HR11 & 2009 \\
H16 & 16 & Huairen, Jilin & 4 & HR8 & 2004 \\
\hline
\end{tabular}




\subsection{Cell Growth Curve of H14 GRE Group}

The growth curve of H14 group was similar to that of HR12 within 12 hours but significantly higher than the latter from the 16-hour point to the 40 -hour point. At the 12-hour point, the cell viability of H14 group was significantly decreased compared with that of Control group.

\subsection{Cell Growth Curve of H16 GRE Group}

The growth curve of H16 group appeared a strong cyclical fluctuation with a period of 8 hours within 32 hours. After that, it grew similarly with the growth curve of H14 group. The cell viability of H16 group was always significantly higher than that of Control group except at the 28-hour point. In particular, the cell viability of H16 group was significantly higher than that of Control group and the other GRE groups at the 4-hour point.

\section{Discussion}

In previous studies, ginsenosides and polysaccharides, mainly contributing to the beneficial biological effects of ginseng [1,2], inhibited the proliferation of K562 cells in vitro experiments separately [4-7]. Furthermore, it was reported that ginsenosides of $100-400 \mu \mathrm{g} / \mathrm{ml}$ (the range of this study was $127-161 \mu \mathrm{g} / \mathrm{ml})[4]$ and polysaccharides of $20-800 \mu \mathrm{g} / \mathrm{ml}$ (the range of this study was 237 $563 \mu \mathrm{g} / \mathrm{ml}$ ) [6] could inhibit the proliferation of K562 cells. However, our experimental data showed that the cell viability of all GRE groups significantly higher than that of control group from the 32-hour point to the 48hour point, meaning that GRE increased rather than inhibited the proliferation of K562 cells. One of the possible reasons is that except for ginsenosides and polysaccharides, there are some nonpolar chemical constituents in the GRE, such as polyacetylenes [8], flavonones and fatty acids, which might contribute to the effects of ginseng $[1,2]$. In this study, these other constituents account for a high percentage in the GRE (from $30.06 \%$ to $63.48 \%$, Table 2) and possibly lead to the strong proliferation on K562 cells or change the combined effects via antagonism and/or synergy [9]. In addition, some certain ginsenosides have been proved to have the ability to stimulate cell proliferation. For example, panaxatriol could significantly stimulate the proliferation of K562 cells at the low concentration but inhibit the proliferation at the middle concentration [10] and ginsenoside $\mathrm{Rg}_{1}$ have the ability to promote the proliferation of neural stem cells $[11,12]$. These special ginsenosides might play an important role in the GRE groups of this study.

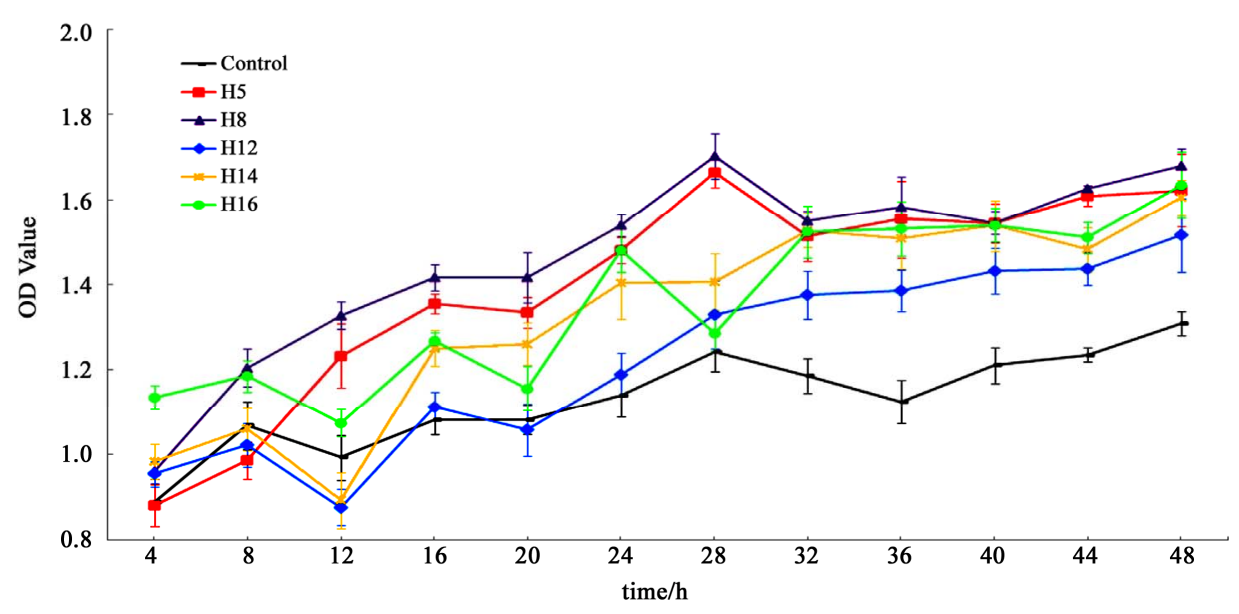

Figure 1. OD values of Control, H5, H8, H12, H14 and H16 groups every 4 hours within 48 hours (n = 6) by using a viability assay named cell counting kit-8. Results are expressed as the mean \pm standard deviations (SD).

Table 2. Content of total Ginseng root extract (GRE) and content of GRE components.

\begin{tabular}{lccccc}
\hline & H5 & H8 & H12 & H14 & H16 \\
\hline Content of GRE in ginseng (\%) $^{\mathrm{a}}$ & 30.87 & 33.35 & 39.98 & 34.36 & 46.43 \\
Content of nonpolar constituents in GRE (\%) $^{\mathrm{b}}$ & 30.06 & 42.31 & 63.48 & 36.15 & 51.63 \\
Content of ginsenosidesin GRE (\%) $^{\mathrm{c}}$ & 13.57 & 15.62 & 12.76 & 15.83 & 16.11 \\
Content of polysaccharides in GRE (\%) $^{\mathrm{d}}$ & 56.37 & 42.07 & 23.76 & 48.02 & 32.26 \\
\hline
\end{tabular}

${ }^{a}$ Extract amount and content from ginseng material of the different age; ${ }^{b}$ Nonpolar constituents extracted by chloroform from the total ginseng extract; Content of nonpolar constituents in the total extract; ${ }^{\circ}$ Ginsenosides constituents extracted by butanol from the ginseng extract that after being extracted by chloroform; Content of ginsenosides in the total extract; ${ }^{\mathrm{d}}$ Polysaccharides constituents, the remains that being removed chloroform and butanol soluble parts from the ginseng total extract; Content of polysaccharides in the total extract. 
Supplementary Table showed that the proportions of ginsenosides, polysaccharides and nonpolar constituents in GRE have remarkable difference in different age groups. These differences may be one reason why K562 cells have different growth curves when adding the GRE with same content but from different age ginsengs. The $\mathrm{H} 5$ and $\mathrm{H} 8$ groups, possessing the similar growth curves, both had a strong proliferation effect on K562 cells compared with Control group within 48 hours. However, there was a strong fluctuation in the growth curve of H16 group within 32 hours.In addition, the cell viability of H12, H14 and H16 groups all decreased sharply at the 12-hour point while that of $\mathrm{H} 5$ and $\mathrm{H} 8$ groups increased significantly at the same time, demonstrating an obvious difference in biological effects between elder GRE groups and younger groups. The elder ginseng has been shown to possess some kinds of gensinosides, such as $\mathrm{Rh}_{2}$ and Compound $\mathrm{K}$, which do not exist in the younger ones [2], so we guess that in addition to the difference in the proportions of total ginsenosides, polysaccharides and nonpolar constituents, the elder ginseng containing some sepcial gensinosides may be one reason for obvious differences in biological effects between elder GRE groups and younger groups. Some evidence from previous studies also clearly indicated that $\mathrm{Rh}_{2}$ and compound $\mathrm{K}$ have strong effects on some cultured cancer cells in vitro experiments [13-18]. Moreover, it has been reported that ginsenosides in ginseng roots will increase slowly in the first several years and then increase sharply in the fifth and sixth years [19].

In this study, if the time interval of detection is 4 hours, the fluctuation of K562 cell growth curves of H12, H14 and $\mathrm{H} 16$ groups, implying the imbalance between proliferation and apoptosis of cells, will be detected. However, if the time interval is 8 hours, the all the growth curves will have no fluctuation. In previous studies, the time interval of detection was 12 hours or even longer [3-7, 20-22]. It is a possible reason that the cyclical fluctuation of cell growth curves was not detected in previous studies. Our results demonstrate that the time interval should be shortened to observe the imbalance between proliferation and apoptosis.

In conclusion, elder ginsengs not only often accumulate more metabolic products than younger individuals, but also the GRE of the former has quite different bioactivity from that of the latter. Although ginsenosides and polysaccharides are regarded as the primary active ingredients of ginseng and can inhibit the proliferation of K562 cells, total GRE can significantly stimulate the proliferation of these cells.

\section{Acknowledgements}

We thank Dr. Jianhui Xie and Dr. Haiyan Zhu for their help in experiments. We also thank Mr. Fugui Lyu and Mr. Shuiwen Wang for their help in sample collection. This study was supported by Science and Technology Community of Shanghai (Traditional Chinese Medicine Research Program, Grant No.08DZ1972500).

\section{REFERENCES}

[1] Chinese Pharmacopoeia Commission, "Pharmacopoeia of People's Republic of China," China Medical Science Press, Beijing, 2005.

[2] T. S. Wang, "China Ginseng," Liaoning Science and Technology Publishing House, Shenyang, 2002.

[3] C. B. Lozzio and B. B. Lozzio, "Human Chronic Myelogenous Leukemia Cell-Line with Positive Philadelphia Chromosome," Blood, Vol. 45, No. 3, 1975, pp. 321-334.

[4] G. W. Zuo, T. Guan, D. L. Chen, C. L. Li, R. Jiang, C. Y. Luo, X. S. Hu, Y. P. Wang and J. W. Wang, "Total Saponins of Panax ginseng Induces K562 Cell Differentiation by Promoting Internalization of the Erythropoietin Receptor," The American Journal of Chinese Medicine, Vol. 37, No. 4, 2009, pp. 747-757.

[5] T. M. Chen, Y. P. Wang, D. L. Chen and J. Li, "Experimental Study on Effect of Apoptosis of K562 Cells Treated with TSPG," Chinese Traditional and Herbal Drugs, Vol. 34, No. 3, 2003, pp. 235-237.

[6] D. L. Chen, Y. G. Liu, Y. P. Wang, T. M. Chen, M. Zheng and R. Jiang, "Effects of Ginseng Polysaccharide on Proliferation and Differentiation of K562 Cells," Acta Academiae Academiae Tertiae, Vol. 27, No. 6, 2005, pp. 517-520.

[7] X. He, R. Jiang, J. Li, G. W. Zuo, C. R. Lei, Y. P. Wang, J. W. Wang and D. L. Chen, "Proliferative Inhibition and Differentiation of Leukemia K562 Cells Induced by Ginsengpolysaccharide in Vitro," Journal of Clinical Rehabilitative Tissue Engineering Research, Vol. 14, No. 49, 2010, pp. 9225-9229.

[8] Y. Z. Zhang, X. N. Lyu, T. Liu, J. P. Luo, W. J. Zhang and Q. Mu, "Analysis of Nonpolar Components from Ginseng of Different Ages," American Journal of Plant Sciences, Vol. 4, No. 1, 2013, pp. 92-97. doi:10.4236/ajps.2013.41014

[9] R. Poduri and N. B. Hemendra, "Antagonism of the Acute Pharmacological Actions of Morphine by Panax ginseng Extract," General Pharmacology, Vol. 21, No. 6, 1990, pp. 877-880. doi:10.1016/0306-3623(90)90448-U

[10] J. M. Jin, W. H. Xu, Y. P. Zhu and R. L. Gao, "Study on the Effect of Panaxatriol on the Sensitivity of Chemical Medicine to Leukemia Cells," Zhejiang Journal of Integrated Traditional Chinese and Western Medicine, Vol. 13, No. 1, 2003, pp. 10-13.

[11] P. W. Zhuang, Y. J. Zhang and T. Pang, "Proliferation Effect of Neural Stem Cell of Ginsenoside Rg1 in Vitro," China Journal of Chinese Materia Medica, Vol. 34, No. 4, 2009, pp. 443-446.

[12] Y. S. Zheng, L. M. Liao, M. Jiang, S. Y. Kou and Y. Li, "Experimental Observation of Ginsenoside Rg1 on the Promotion of the Proliferation of Neural Stem Cells," 
China National Journal of New Gastroenterology, Vol. 6, No. 12, 2011, pp. 1021-1024.

[13] Y. Kikichi, H. Sasa, T. Kita, J. Hirata, T. Tode and I. Nagata, "Inhibition of Human Ovarian Cancer Cell Proliferation in Vitro by ginsenoside $\mathrm{Rh}_{2}$ and Adjuvant Effects to Cisplatin in Vivo," Anticancer Drug, Vol. 2, No. 1, 1991, pp. 63-67. doi:10.1097/00001813-199102000-00009

[14] J. A. Park, K. Y. Lee, Y. J. Oh, S. I. Kim and S. K. Lee, "Activation of Caspase-3 Protease via a Bcl-2-Insensitive Pathway during the Process of Ginsenoside $\mathrm{Rh}_{2}$-Induced Apoptosis," Cancer Letters, Vol. 121, No. 1, 1997, pp. 73-81. doi:10.1016/S0304-3835(97)00333-9

[15] J. I. Oh, K. H. Chun, S. H. Joo, Y. T. Oh and S. K. Lee, "Caspase-3-Dependent Protein Kinase C Delta Activity Is Required for the Progression of Ginsenoside- $\mathrm{Rh}_{2}$-Induced Apoptosis in SK-HEP-1 Cells," Cancer Letters, Vol. 230, No. 2, 2005, pp. 228-238. doi:10.1016/j.canlet.2004.12.043

[16] C. C. Cheng, S. M. Yang, C. Y. Huang, J. C. Chen, W. M. Chang and S. L. Hsu, "Molecular Mechanisms of Ginsenoside $\mathrm{Rh}_{2}$-Mediated $\mathrm{G}_{1}$ Growth Arrest and Apoptosis in Human Lung Adeno-Carcinoma A549 Cells," Cancer Chemotherapy and Pharmacology, Vol. 55, No. 6, 2005, pp. 531-540. doi:10.1007/s00280-004-0919-6

[17] D. Y. Kim, M. W. Park, H. D. Yuan, H. J. Lee, S. H. Kim and S. H. Chung, "Compound K Induces Apoptosis via CAMK-IV/AMPK Pathways in HT-29 Colon Cancer Cells," Journal of Agricultural and Food Chemistry, Vol. 57, No. 22, 2009, pp. 10573-10578.

\section{doi:10.1021/jf902700h}

[18] S. Chae, K. A. Kang, W. Y. Chang, M. J. Kim, S. J. Lee, Y. S. Lee, H. S. Kim, D. H. Kim and J. W. Hyun, "Effect of Compound K, a Metabolite of Ginseng Saponin, Combined with $\gamma$-Ray Radiation in Human Lung Cancer Cells in Vitro and in Vivo," Journal of Agricultural and Food Chemistry, Vol. 57, No. 13, 2009, pp. 5777-5782. doi:10.1021/jf900331g

[19] F. Soldati and O. Tanaka, "Panax ginseng: Relation between Age of Plant and Content of Gensenosides," Planta Medica, Vol. 51, No. 4, 1984, pp. 351-352. doi:10.1055/s-2007-969729

[20] G. B. Zhou, H. Kang, L. Wang, L. Gao, P. Liu, J. Xie, F. X. Zhang, X. Q. Weng, Z. X. Shen, J. Chen, L. J. Gu, M. Yan, D. E. Zhang, S. J. Chen, Z. Y. Wang and Z. Chen, "Oridonin, a Diterpenoid Extracted from Medicinal Herbs, Targets AML1-ETO Fusion Protein and Shows Potent Antitumor Activity with Low Adverse Effects on t $(8 ; 21)$ Leukemia in Vitro and in Vivo," Blood, Vol. 109, No. 8, 2007, pp. 3441-3450. doi:10.1182/blood-2006-06-032250

[21] W. X. Cao, Y. P. Wang, Q. Liu, R. Jiang and T. M. Chen, "Effects of TSPG on Apoptosis and Expressions of Fas and FasL in K562 Cells," Acta Academiae Academiae Tertiae, Vol. 27, No. 6, 2005, pp. 525-528.

[22] C. R. Lei, R. Jiang, H. N. Wang, X. He, G. W. Zuo, D. L. Chen, T. Guan and J. W. Wang, "Effects of Total Saponins of Panax ginseng on Proliferation and Differentiation of K562 Cells," Laser Journal, Vol. 32, No. 2, 2011, pp. 69-73. 
Supplementary Table. OD values of control, H5, H8, H12, H14 and H16 groups within 48 hours.

\begin{tabular}{|c|c|c|c|c|c|c|}
\hline & Control & H5 & H8 & H12 & H14 & H16 \\
\hline $4 \mathrm{~h}$ & $0.888 \pm 0.0549^{\text {cef }}$ & $0.881 \pm 0.049^{\text {cdef }}$ & $0.960 \pm 0.0281^{\mathrm{abf}}$ & $0.954 \pm 0.0300^{\mathrm{bf}}$ & $0.984 \pm 0.0407^{\mathrm{abf}}$ & $1.134 \pm 0.0280^{\text {abcde }}$ \\
\hline $8 \mathrm{~h}$ & $1.068 \pm 0.0564^{\mathrm{bcf}}$ & $0.986 \pm 0.0430^{\text {acef }}$ & $1.204 \pm 0.0454^{\text {abde }}$ & $1.022 \pm 0.0512^{\mathrm{cf}}$ & $1.059 \pm 0.0492^{\mathrm{bcf}}$ & $1.184 \pm 0.0377^{\mathrm{abde}}$ \\
\hline $12 \mathrm{~h}$ & $0.993 \pm 0.0528^{\text {bcdef }}$ & $1.233 \pm 0.0751^{\text {acdef }}$ & $1.326 \pm 0.0320^{\mathrm{abdef}}$ & $0.877 \pm 0.0418^{\mathrm{abcf}}$ & $0.892 \pm 0.0643^{\mathrm{abcf}}$ & $1.074 \pm 0.0320^{\text {abcde }}$ \\
\hline $16 \mathrm{~h}$ & $1.080 \pm 0.0333^{\text {bcef }}$ & $1.354 \pm 0.0229^{\text {acdef }}$ & $1.417 \pm 0.0310^{\text {abdef }}$ & $1.112 \pm 0.0342^{\text {bcef }}$ & $1.251 \pm 0.0421^{\mathrm{abcd}}$ & $1.268 \pm 0.0205^{\mathrm{abcd}}$ \\
\hline $20 \mathrm{~h}$ & $1.081 \pm 0.0346^{\text {bcef }}$ & $1.334 \pm 0.0359^{\text {acdef }}$ & $1.415 \pm 0.0589^{\mathrm{abdef}}$ & $1.057 \pm 0.0610^{\mathrm{bcef}}$ & $1.260 \pm 0.0497^{\mathrm{abcdf}}$ & $1.156 \pm 0.0521^{\mathrm{abcde}}$ \\
\hline $24 \mathrm{~h}$ & $1.138 \pm 0.0508^{\text {bcef }}$ & $1.479 \pm 0.0307^{\mathrm{acd}}$ & $1.539 \pm 0.0252^{\text {abdef }}$ & $1.187 \pm 0.0510^{\text {bcef }}$ & $1.404 \pm 0.0853^{\mathrm{acd}}$ & $1.480 \pm 0.0509^{\mathrm{acd}}$ \\
\hline 32 h & $1.186 \pm 0.0409^{\text {bcdef }}$ & $1.513 \pm 0.0595^{\mathrm{ad}}$ & $1.550 \pm 0.0225^{\mathrm{ad}}$ & $1.375 \pm 0.0558^{\mathrm{abcef}}$ & $1.527 \pm 0.0403^{\mathrm{ad}}$ & $1.524 \pm 0.0621^{\mathrm{ad}}$ \\
\hline $36 \mathrm{~h}$ & $1.124 \pm 0.0519^{\text {bcdef }}$ & $1.553 \pm 0.0901^{\mathrm{ad}}$ & $1.583 \pm 0.0707^{\mathrm{ad}}$ & $1.386 \pm 0.0490^{\text {abcef }}$ & $1.509 \pm 0.0731^{\mathrm{ad}}$ & $1.531 \pm 0.0643^{\mathrm{ad}}$ \\
\hline $40 \mathrm{~h}$ & $1.210 \pm 0.0425^{\mathrm{bcdef}}$ & $1.543 \pm 0.0462^{\mathrm{ad}}$ & $1.545 \pm 0.0260^{\mathrm{ad}}$ & $1.432 \pm 0.0529^{\mathrm{abcef}}$ & $1.538 \pm 0.0603^{\mathrm{ad}}$ & $1.539 \pm 0.0397^{\mathrm{ad}}$ \\
\hline $44 \mathrm{~h}$ & $1.235 \pm 0.0163^{\text {bcdef }}$ & $1.609 \pm 0.0244^{\text {adef }}$ & $1.625 \pm 0.0068^{\text {adef }}$ & $1.437 \pm 0.0388^{\mathrm{abcf}}$ & $1.481 \pm 0.0534^{\mathrm{abc}}$ & $1.510 \pm 0.0374^{\mathrm{abcd}}$ \\
\hline $48 h$ & $1.308 \pm 0.0276^{\text {bcdef }}$ & $1.622 \pm 0.0856^{\mathrm{a}}$ & $1.681 \pm 0.0397^{\text {ade }}$ & $1.515 \pm 0.0866^{\mathrm{acf}}$ & $1.604 \pm 0.0418^{\mathrm{ac}}$ & $1.635 \pm 0.0774^{\mathrm{ad}}$ \\
\hline
\end{tabular}

Values are expressed as mean \pm SD. ${ }^{a}$ means $\mathrm{P}<0.05$ vs. Control group. ${ }^{b}$ means $\mathrm{P}<0.05$ vs. H5 group. ${ }^{\mathrm{c}}$ means $\mathrm{P}<0.05$ vs. H8 group. ${ }^{\mathrm{d}}$ means $\mathrm{P}<0.05$ vs. H12 group. ${ }^{\mathrm{e}}$ means $\mathrm{P}<0.05$ vs. $\mathrm{H} 14$ group. ${ }^{\mathrm{f}}$ means $\mathrm{P}<0.05$ vs. H16 group. 